\title{
e-interview
}

\section{Frank Njenga}

Frank Njenga is Consultant Psychiatrist at Upper Hill Medical Center, Nairobi, Kenya, and President of the African Association of Psychiatrists and Allied Professions. He trained at the University of Nairobi and the Maudsley Hospital. His special interests include health policy in Africa, mental health and the media, and attention-deficit hyperactivity disorder in adults.

If you were not a psychiatrist, what would you do?

I would be a politician advocating for human rights. I would probably have trained as a lawyer and weaved my way through the United Nations system on issues of truth, peace, justice and conflict resolution!

What has been the greatest impact of your profession on you personally? Attention-deficit hyperactivity disorder. In the last 5 years I have discovered a mental illness for which effective interventions exist and that transform young people from drug-addicted academic and social failures to really successful human beings.

\section{Do you feel stigmatised by your profession?}

Only the poorly educated ignorant snobs among us.

\section{What are your interests outside of} work?

Golf, family, travel and politics (at the level of world psychiatry). Reading and writing children's books and the media.

Who was your most influential trainer, and why?

Michael Shephard: he was clever, shy, honest and kind, and hid from me until the day of my departure from the Maudsley; a fact that he liked me. When I first worked for him, I was sure he had conspired with the social worker to finish me!

What job gave you the most useful training experience?

The Bethlem Royal Hospital general psychiatry ward where I worked with Edward Hare (Consultant), Robin Murray (Senior Registrar) and Tony Holland (fellow Registrar).

Which publication has influenced you most?

Fish's Psychopathology, and Franz Fanon's TheWretched of the Earth. At the age of 16,

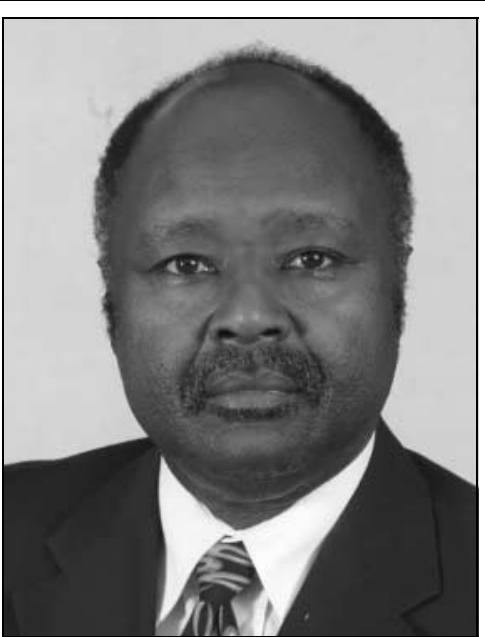

What conflict of interest do you encounter most often?

Between drug company offers of support for public education programmes and the need to remain faithful to the science.

What is the role of the psychiatrist in countries emerging from conflict? Conflict resolution, participation in truth, justice and reconciliation; education of politicians on their roles in peace building. Management of settlement programmes.

What is the most important advice you could offer to a new trainee?

Like a good foundation, good training is a lifetime investment.

What are the main ethical problems that psychiatrists will face in the future?

Psychiatric research in persons with mental illness, mental health services to poor, hungry people.

I read The Wretched of the Earth and saw the link between liberty, poverty and mental health. I decided to become a psychiatrist like Fanon and have never regretted that decision for a moment.

How has the political environment influenced your work?

It has made the link between menta health and poverty very clear and increased my determination to engage politicians positively for the sake of mental health.

What part of your work gives you the most satisfaction?

Getting boys and girls, and young men and women back to school and university.

\section{What do you least enjoy?}

Paperwork! Doing medical reports.

What is the most promising opportunity facing the profession?

Marketing itself as a branch of medicine that gets people's lives back together again, not one that only treats chronic disability.

\section{What is the greatest threat?}

The defensive stance by psychiatrists in the face of stigma. Poor training of psychiatrists leading to a self-fulfilling prophecy - that we are a second-rate discipline.

What single change would substantially improve quality of care? Increasing the number of medical professionals who know how to recognise and treat depression.
Do you think psychiatry is brainless or mindless?

Some of us behave as though we are brainless, others as though we are mindless. Our patients can tell the difference.

What is the role of the psychiatrist in rebuilding healthcare systems? To remain clear and focused on what we can and cannot do or offer!

What single change to mental health legislation would you like to see? Eliminate the discrimination by medical insurers in relation to mental illness.

\section{What single area of psychiatric} practice is most in need of development?

More child and adolescent psychiatrists.

What single area of psychiatric research should be given priority? Identification of the sources of conflict among tribes, nations and families. A large number of mental disorders arise from discord among these groups.

How would you like to be remembered?

A Maudsley-trained psychiatrist who went back to Africa and made a difference to the practice of mental healthcare in Africa and the world.

\section{Dominic Fannon}

doi: 10.1192/pb.bp.108.022921 